\title{
Rapid diagnosis of ocular herpes simplex infections
}

\author{
P A Asbell, M A Torres, T Kamenar, E J Bottone
}

\begin{abstract}
Background-The Surecell herpes (HSV) test kit is a test for detecting the presence of herpes simplex viral antigen by, means of a monoclonal antibody based immunoassay. The test has proved to be highly sensitive and specific in diagnosing genital, oral, and dermatological herpes infections.

Methods-In this study, samples from patients with ocular keratitis were evaluated by tissue cultures and the Surecell test. The eyes of New Zealand rabbits were then inoculated with HSV type 1 acute keratitis, acute Staphylococcus keratitis, acute Pseudomonas keratitis, and HSV type 1 postkeratitis (healed corneas). Tear film samples collected from each eye with a cotton swab were evaluated by routine culture (A-549 monolayers) and by the Surecell test with and without prior placement of the swab in Hank's medium.

Results-The Surecell system had a 70\% sensitivity and a $100 \%$ specificity in the detection of HSV antigen in ocular infections, and was shown to be a quick, efficient, and accurate method of testing for HSV antigen in humans.

Conclusion-These results from humans and rabbits indicate that the Surecell test, which requires no special equipment, can be a useful in office adjunct in the clinical diagnosis of ocular herpes simplex. (Br f Ophthalmol 1995; 79: 473-475)
\end{abstract}

There can be a high degree of overlap between the ocular manifestations of herpes simplex virus (HSV) and those of other infections. Rapid, specific diagnosis of HSV is essential to avoid the complications that can arise from misdiagnosis and inappropriate treatment. Currently, tissue culture provides the most reliable diagnosis of ocular HSV. However, this method is not only time consuming and expensive, but requires technology that is not available in most office settings. In this study we evaluated the accuracy of the Surecell HSV test kit, a monoclonal antibody based enzyme immunoassay system manufactured by the Kodak Co (Rochester, NY, USA), in detecting HSV antigens in eyes with active herpes infection.

\section{Materials and methods}

\section{CLINICAL STUDY}

The subjects were patients clinically diagnosed as having active and latent ocular herpes, bacterial keratitis, non-specific keratoconjunctivitis, corneal erosion, or miscellaneous corneal conditions. Within 5 minutes after the administration of one drop of proxymetacaine (proparacaine) 1\%, two tear film samples were collected from each eye by swabbing the corneal lesion and the conjunctival cul de sac. Each cotton tipped swab was retained in the fornix for 20 seconds to permit maximum tear film absorption. In each set of two swabs, one was used for the direct Surecell test and the other for tissue culture.

The Surecell test was performed according to the manufacturer's directions (package insert). In brief, each sample was placed in a tube containing $1 \mathrm{ml}$ of buffered solution to extract HSV antigen. After 1 minute in the buffered solution, the sample was filtered into each of the three wells of the test device. Well No 1 is for the negative control, to which the negative control conjugate is added; well No 2 is for the test sample. Well No 3, for the positive control, has ultraviolet inactivated HSV 1 and 2 antibody incorporated into its membrane; thus, if $\mathrm{HSV}$ antigen is present it will bind to the well membrane.

To perform the Surecell test, a conjugated solution of non-HSV antibody of an isotype similar to the anti-HSV antibody is added to the negative well (No 1). An enzyme conjugated anti-HSV monoclonal antibody solution is added to well Nos 2 and 3. An enzyme substrate conjugated to a dye is then added to each well. In the presence of antibody-antigen complex, the substrate releases the dye, causing a white to red colour reaction on the membrane. A positive test is indicated by a uniform pink to red colour in the sample well (No 2) as compared with a lack of colour in the negative control. Equal coloration in the sample well and the negative control well is interpreted as a negative result. The positive control well (No 3) always shows the pink-red colour. The same procedure was followed with the samples in transport medium except that, in the first step, $0.5 \mathrm{ml}$ of extraction solution was combined with $0.5 \mathrm{ml}$ of transport medium.

To avoid bias, one investigator collected and coded all specimens and another investigator performed the Surecell tests. The specimens for tissue culture in the virology laboratory were identified only by code number. Neither the second investigator nor personnel in the virology laboratory were aware of sample identities.

ANIMAL STUDY

Eyes of New Zealand albino rabbits (50 eyes) were divided into five groups of 10 . Then, in a 
Table 1 Comparison between results obtained with the Surecell test and tissue culture in the diagnosis of ocular herpes simplex in humans

\begin{tabular}{lll}
\hline & $\begin{array}{l}\text { Surecell test } \\
\text { direct swab } \\
(n)\end{array}$ & $\begin{array}{l}\text { Tissue } \\
\text { culture } \\
(n)\end{array}$ \\
\hline Clinical diagnosis & $4 / 5$ & $5 / 5$ \\
Active HSV & $0 / 5$ & $0 / 5$ \\
Latent HSV & $0 / 12$ & $1 / 12$ \\
Non-specific KC & $0 / 2$ & $0 / 2$ \\
Epithelial defects after PKP† & $0 / 2$ & $0 / 2$ \\
Recurrent erosions & $0 / 1$ & $0 / 1$ \\
Peripheral keratitis & $0 / 1$ & $0 / 1$ \\
Acanthamoeba keratitis & & \\
\hline
\end{tabular}

${ }^{\star} \mathrm{KC}=$ keratoconjunctivitis; $\mathrm{P} \mathrm{P} \mathrm{P}=$ penetrating keratoplasty.

manner that complied with required standards for the care and use of laboratory animals, the eyes were inoculated as follows:

Group I: HSV type 1 (Re strain) acute keratitis Group II: HSV type 1 (Re strain), eyes previously infected but now healed

Group III: Pseudomonas aeruginosa isolated from patients with keratitis

Group IV: Staphylococcus aureus isolated from patients with keratitis

Group $V$ : controls (that is, no infection, no treatment).

Sample collection was done in the same manner as in the human study except that an additional swab was collected from each eye. In each case, this swab was placed in $1.5 \mathrm{ml}$ of Hank's medium coded, and submitted to the virology laboratory for tissue culture inoculation (A-549 monolayers). The cultured specimens were read daily for 10 days to determine cytopathic effect. The direct and indirect Surecell test procedures were performed in the same manner as in the human study. After data collection, the codes were broken and the data analysed.

\section{Results}

CLINICAL STUDY

Table 1 shows the results of the Surecell test and tissue culture in diagnosing human ocular surface diseases. Samples from three patients who, on the basis of clinical observations, were thought to have HSV keratitis, as well as one patient with vesicular eruption on the eyelids, yielded positive results by the Surecell direct swab test. All four of these patients were also positive for HSV by tissue culture. One patient who had chronic unilateral conjunctivitis had a negative Surecell test, although on day 14 the culture showed a positive cytopathic effect characteristic of HSV. Swabs from all other

Table 2 Positive results obtained with the Surecell test and tissue culture in the diagnosis of ocular infections in rabbits

\begin{tabular}{llll}
\hline \multicolumn{4}{l}{ Surecell HSV test } \\
\cline { 2 - 4 } & $\begin{array}{l}\text { Direct } \\
\text { swab } \\
(10 \text { samples })\end{array}$ & $\begin{array}{l}\text { Swab in } \\
\text { transport medium } \\
(10 \text { samples })\end{array}$ & $\begin{array}{l}\text { Viral } \\
\text { culture } \\
(10 \text { samples })\end{array}$ \\
\hline Active HSV & 7 & 5 & 10 \\
Latent HSV & 0 & 0 & 0 \\
Pseudomonas & 0 & 0 & 0 \\
Staphylococcus & 0 & 0 & 0 \\
Control & 0 & 0 & 0 \\
\hline
\end{tabular}

patients with non-herpetic lesions were negative by both tissue culture and the Surecell test.

ANIMAL STUDY

All 10 eyes with active HSV infection yielded positive HSV cultures (Table 2). Only seven of these eyes were positive by the Surecell direct swab method; five were positive by the Surecell method when the swab had been placed in Hank's medium before testing. All other samples were negative by both tissue culture and Surecell. These results represent a sensitivity of $70 \%$ for the Surecell direct swab test and $50 \%$ when the test was done on swabs that had been transported in Hank's medium. The specificity of the test was $100 \%$; there were no false positive results.

\section{Discussion}

Several tests for the diagnosis of ocular HSV infections have been introduced in recent years, but no single test has been universally accepted for that purpose. Thus, the development of a simple, rapid, and specific test for the diagnosis of such infections remains a major goal in ocular microbiology and immunology.

Viral culture, the method most widely used for definitive diagnosis of HSV infections, yields variable results that often underestimate the true prevalence of HSV infection. ${ }^{12}$ Other techniques that can be used to document ocular HSV infections include indirect immunofluorescence, ${ }^{4}$ modified immunoperoxidase, ${ }^{5}$ enzyme immunofiltration, ${ }^{6}$ enzyme immunoassay, ${ }^{78}$ and latex agglutination. ${ }^{9}$ However, most of these tests are complex and, if results are to be reliable, must be done by specifically trained personnel.

Kowalski and Gordon ${ }^{10}$ compared four immunological tests for detecting HSV in ocular specimens. Of these tests, the Herpcheck and enzyme immunofiltration proved more sensitive than latex agglutination and enzyme immunoassay in detecting HSV. Moreover, both the Herpcheck and enzyme immunofiltration tests were $100 \%$ specific. Recently, Dunkel and coworkers reported that results obtained with the Herpcheck method had a $100 \%$ correlation with clinical diagnosis, whereas virus culture had a $90 \%$ correlation with clinical diagnosis during active HSV infection. ${ }^{3}$

According to Kodak, the Surecell test, when applied to specimens from genital and external non-genital lesions, has a sensitivity of $67-100 \%$ and a specificity of $96-100 \% .^{11}$ In our study of human ocular specimens, the test had a sensitivity of $80 \%$ and a specificity of $96 \%$. In our animal study, the Surecell test had a sensitivity of $70 \%$ and a specificity of $100 \%$. The test is quick and easy to perform, taking only about 20 minutes, requires no laboratory equipment, and is easy to interpret. Moreover, the test yielded no false positive results. The test has produced negative results in the presence of several micro-organisms, including multiple species of bacteria, as well as varicella zoster virus (data on file with Kodak). 
In contrast with our results, Portnov and Kowalski, in their evaluation of the Surecell test on humans with ocular disease, found that it had a sensitivity of only $37.5 \%$ and a specificity of $81 \cdot 3 \% .^{12}$ However, these authors tested only samples from viral transport media, whereas we also used direct swab testing. It is likely that a transport medium dilutes the antigen concentration obtained by direct swab and thus lowers the sensitivity of the test. This possibility is supported by the fact that in our rabbit study the Surecell test had a sensitivity of $70 \%$ when it was performed directly on swabs, but only $50 \%$ when it was performed on swabs that had been in transport medium. A potentially related point is that the interval between the onset of symptoms in our human subjects and the time of testing was, in all cases, less than 5 days. Although Portnov and Kowalski did not specify the interval between the onset of symptoms and the time of testing in their study, it is known that the highest concentration of antigen is available early in the course of herpes infection.

Our sample populations were not large enough to allow definitive conclusions regarding the effectiveness of the Surecell test in diagnosing ocular herpes infections. None the less, the promising results of our investigation justify further assessment of the usefulness of this test.
Funded in part by Research to Prevent Blindness Inc.

The authors thank D Paul for his technical assistance in this project.

1 Zaitseva NS, Muravieva TV, Vinogradova VL, Shubladze AK, Maevskaya TM, Kasparov AA, et al. Comparative evaluation of methods for laboratory diagnosis of herpetic eye disease. Am $\mathcal{F}$ Ophthalmol 1973; 75: 997-1003.

2 Coleman VR, Thygeson P, Dawson CR, Jawetz E. Isolation of virus from herpetic keratitis. Influence of idoxuridine on isolation rates. Arch Ophthalmol 1969; 81: 22-4.

3 Dunkel EC, Pavan-Langston D, Fitzpatrick K, Cukor G. Rapid detection of Herpes simplex virus (HSV) antigen in human ocular infections. Curr Eye Res 1988; 7: 661-6.

4 Schwab IR, Raju VK, McClung J. Indirect immunofluorescent antibody diagnosis of Herpes simplex with fluorescent antibody diagnosis of Herpes simplex with
upper tarsal and corneal scrapings. Ophthalmology 1986; 96: 752-6.

5 Catalano RA, Webb RM, Smith RS, Duke MA. A modified immunoperoxidase method for rapid diagnosis of herpes simplex I keratitis. Am f Clin Pathol 1986; 96: 752-6.

6 Cleveland PH, Richman DD, Redfield DC, Disharoon DR, Binder PS, Oxman MN. Enzyme immunofiltration technique for rapid diagnosis of herpes simplex virus eye infec-

7 Lee SM, Taguchi F. Rapid identification and typing of Herpes simplex virus by a new enzyme immunoassay with peroxidase-labelled complement C 1 q. Arch Virol 1989; 108: 247-57.

8 Denoyal GA, Gaspar A, Nouyrigat C. Enzyme immunoassay for measurements of antibodies to Herpes simplex virus infection: comparison with complement fixation, immunofluorescent antibody, and neutralization techniques. F Clin Microbiol 1980; 11: 114-9.

9 Storch GA, Reed CA, Dahe ZA. Evaluation of latex agglutination test for Herpes simplex virus. $\mathcal{F}$ Clin Microbiol 1988; 26: 787-8.

10 Kowalski RP, Gordon YJ. Evaluation of immunologic tests for the detection of ocular herpes simplex virus. Ophthalmology 1989; 96: 1583-6.

11 Kodak, SURECELL Herpes (HSV) Test Kit. Package Insert. Eastman Kodak Co, Clinical Products Division, Insert. Eastman Kodak Co,

12 Portnov SL, Kowalski R, Karenchak L, Arfa R. Evaluation of the Kodak Surecell test for ocular HSV diagnosis. ARVO Abstract no 1086, Invest Ophthalmol Vis Sci 1990; 31: 221 . 